\title{
Chemical Modification of Scraped Tires through Grafting with 2-Acrylamido-2-methylpropansulfonic Acid
}

\author{
Yassin A. Aggour ${ }^{1,2^{*}}$, Ayied S. Al-Shihri ${ }^{1}$, Mohamed R. Bazzet ${ }^{1}$ \\ ${ }^{1}$ Chemistry Department, College of Science, King Khalid University, Abha, Kingdom of Saudi Arabia \\ ${ }^{2}$ Chemistry Department, College of Science, Damietta University, New-Damietta, Egypt \\ Email: *Yassina9@yahoo.com
}

Received April 15, 2013; revised June 6, 2013; accepted June 25, 2013

Copyright (C) 2013 Yassin A. Aggour et al. This is an open access article distributed under the Creative Commons Attribution License, which permits unrestricted use, distribution, and reproduction in any medium, provided the original work is properly cited.

\begin{abstract}
Scrap vulcanized rubber is amongst a bigger waste polymers. It does not decompose easily owing to its cross linked structure. Modification of scrap tires powder by the grafting with 2-acrylamido-2-methylpropanesulfonic acid (AMPS) is described. The grafting is achieved through free radical initiation. The effects of different amount of monomer and initiator were examined. Also the influence of reaction time and temperature were investigated. The grafted waste rubber was characterized by FT/IR, SEM and DSC measurements. The proposed mechanism of the grafting reaction is discussed. From DSC and SEM studies of WR-g-AMPS compared with PAMPS and WR, the results show that the particle size and crystallinity were enhanced for the grafted copolymers. The obtained modified scraped tires will used as an ion exchanger for the future applications.
\end{abstract}

Keywords: Chemical Modification; Scraped Tires; Grafting Polymer Characterization; 2-Acrylamido-2-methylpropanesulfonic Acid

\section{Introduction}

Pollution of environments with industrial and permanent waste materials is of the biggest problem for civilization at the present and future time. Scrap rubbers, especially scrap tires cause significant environmental problems due to their high thermal resistivity to nature conditions. To reduce these wastes from the environment and reduce costs of rubber raw material, attempts were being made to recycle of waste rubber [1]. There are two main ways to consume waste rubber. The first is the interaction or pyrolitic degradation of waste rubber to basic chemicals $[2,3]$. The second is grinding the waste to form granulate or regenerate to produce technically less demanding rubber $[4,5]$. Reclaiming of products by devulcanization has been attempted [6,7]. Recently previous researchers modified the surface of rubber crumb with ozone [8], the enhancement of mechanical properties by blending of polypropylene with ground waste rubber powder were done [9]. Also scraped tires are used as adsorbents for adsorption of organic and inorganic solutes [10]. However, these methods are not appropriate to handle waste rubber, due to difficulties to use and to result of other

${ }^{*}$ Corresponding author. environmental problems, such as air pollution or flotation to the surface. Therefore recycling of waste rubber has been widely investigated as an alternative method. Reuse of waste rubber by grafting reaction is studied by some researchers [11-13]. Grafting of vinyl monomers to polydiene based rubbers by free radical initiator are successful reported method [14]. Recently in our laboratory we modified the waste vulcanized rubber by chlorination and amination reactions [15]. Also the surface modification of waste tire by grafting with styrene and maleic anhydride are studied at different reaction conditions [16].

2-Acrylamido-2-methylpropanesulfonic acid is relatively strong acid [17] that had a wide variety of applications $[18,19]$, including packing films, foam stabilizers, photographic materials and water absorbents. The present studies are aiming to graft 2-acrylamido-2-methylpropanesulfonic acid onto previously sulfonated waste rubber granular, by free radial initiation method. The grafting reactions are studied as a function of time, temperature, initiator concentration and AMPS quantity. The products obtained are characterized by FT/IR, DSC, and SEM. A suggested reaction mechanism of the grafting is given. The obtained grafted materials will be used for further studies by our research group. 


\section{Experimental Section}

\subsection{Materials}

2-Acrylamido-2-methylpropanesulfonic acid (AMPS) (Merck) was used without further purification. Hydrogen peroxide $\left(\mathrm{H}_{2} \mathrm{O}_{2}\right)$ was used as initiator (Fluka) The ground discarded tire rubber with an average particle size of 0.2 $0.4 \mathrm{~mm}$ was prepared from waste tires SBR (USA). The other chemicals used were of analytical grade and used as received.

\subsection{Sulfonation Reaction}

Sulfonaed waste rubber (SWR) was prepared by cooking five grams of the clean and dry granulated WR in $250 \mathrm{ml}$ conc. $\mathrm{H}_{2} \mathrm{SO}_{4}$ for $24 \mathrm{~h}$, followed by drop wise addition of Oloum and heating at $80^{\circ} \mathrm{C}$ for $8 \mathrm{~h}$. Filtration and washing using low in gradient $\mathrm{H}_{2} \mathrm{SO}_{4}$ and distilled water were performed, and finally the SWR was dried in air.

\subsection{Grafting Reaction}

Grafting of AMPS onto sulfonated WR was carried out in aqueous solution using $\mathrm{H}_{2} \mathrm{O}_{2}$ as an initiator. Reactions were carried out in a closed steel reactor using different quantities of AMPS, $\mathrm{H}_{2} \mathrm{O}_{2}$ and at different times and temperatures. The yields were obtained by precipitation in acetone, then filtration and washing with distilled water, drying and weighing until constant weight.

\subsection{Estimating of Grafting Yield}

The graft yields were characterized by the following parameters:

Grafting percentage: $(\mathrm{Gp} \%)=(\mathrm{A}-\mathrm{B} / \mathrm{B}) \times 100$

Weight conversion: $(\mathrm{WC} \%)=(\mathrm{A} / \mathrm{B}) \times 100$

where $\mathrm{A}$, and $\mathrm{B}$ are the weights of grafted product, and WR respectively.

\subsection{Characterization Techniques}

Infrared spectra were measured on Jasco 460 plus FT-IR spectrometer, in the range of $4000-400 \mathrm{~cm}^{-1}$. The rubber samples were obtained as $\mathrm{KBr}$ disc, using hydraulic press at pressure $10 \mathrm{kpa}$. Thermal date was obtained by using Shimadzu DSC-50 instrument. Ten milligrams of the sample were put into an aluminum pan with a cover. The samples were cooled, before heating up to $500^{\circ} \mathrm{C}$ at rate of $10^{\circ} \mathrm{C} / \mathrm{min}$. The microstructure of the polymers was examined by scanning electron microscope (SEM), 6360 (LA).

\section{Results and Discussion}

\subsection{Determination of Optimum Reaction Conditions}

The grafting of AMPS were performed onto previously sulfonated WR, the sulfonation was done aiming to convert the waste materials to be more hydrophilic. These will expected to enhance the penetration of AMPS chain within the skeleton of rubber. In addition, the AMPS was chosen for the grafting, due to its functional groups which are suitable for further applications, progressed in our laboratory.

The grafting was studied under various reaction conditions to discover those conditions most suitable for the grafting. The variables studied were reaction time, grafting temperature, and the concentrations of both initiator $\left(\mathrm{H}_{2} \mathrm{O}_{2}\right)$, and AMPS.

\subsubsection{Influence of Reaction Time}

The reaction time is one of the important factors controlling the grafting. Figure 1 shows the effect of reaction time on the grafting at $90^{\circ} \mathrm{C}$ and at constant concentrations of AMPS and $\mathrm{H}_{2} \mathrm{O}_{2}$. It is clear from the figure that the grafting yield enhanced by time, reach to its maximum after seven days. These are attributed to, at the shorter time (for one day); it's not enough for penetration of AMPS within the waste rubber. However at the longer reaction time (for 11 days) both the GP\% and $\mathrm{WC} \%$ decreased, which may be due to dissociation of the grafted materials [20].

\subsubsection{Influence of Temperature}

The effect of reaction temperatures on the grafting were carried out at $60,75,90,110$ and $125^{\circ} \mathrm{C}$, keeping the other variables constant. The results are given in Figure 2; which shows that the grafting yields were increased by rising the temperature up to $90^{\circ} \mathrm{C}$; these will lead to high rate of dissociation of initiator and initiation the reaction [21]. However at the higher temperature the GP\% is decreased. These can be attributed to thermal dissociation of the grafted waste rubber [22].

\subsubsection{Influence of Initiator Concentration}

The results of grafting of AMPS onto sulfonated WR, while varying the $\mathrm{H}_{2} \mathrm{O}_{2}$ loading from 0.2 to $0.5 \mathrm{~g} / \mathrm{ml}$ are indicated in Figure 3. As the $\mathrm{H}_{2} \mathrm{O}_{2}$ concentration increase, the grafting yields are increased. This can be attributed to increase of $\mathrm{OH}$ radial, which activate the WR backbone, followed by grafting of AMPS. Whatever, a

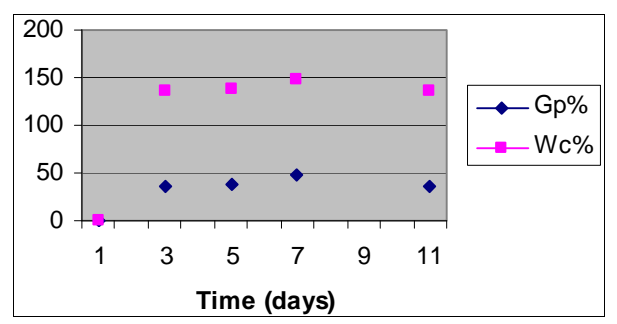

Figure 1. Effect of reaction time on the grafting of AMPS onto WR, (at $90^{\circ} \mathrm{C} ; \mathrm{H}_{2} \mathrm{O}_{2} 3 \mathrm{ml} / 10 \mathrm{ml}$; AMPS $1.5 \mathrm{~g} / 10 \mathrm{ml}$ ). 


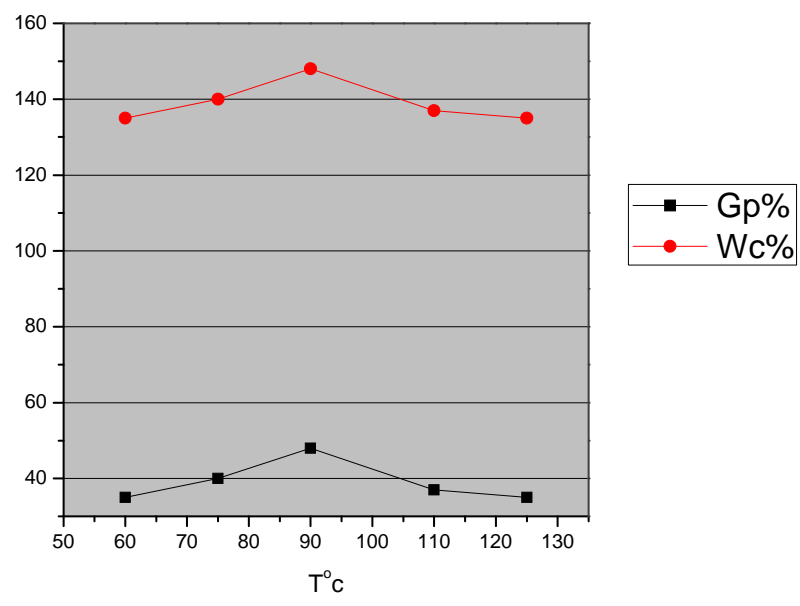

Figure 2. Effect of temperature on grafting of AMPS onto WR $\left(\mathrm{H}_{2} \mathrm{O}_{2} 3 \mathrm{ml} / 10 \mathrm{ml}\right.$; AMPS $1.5 \mathrm{~g} / 10 \mathrm{ml}$; time 7 days).

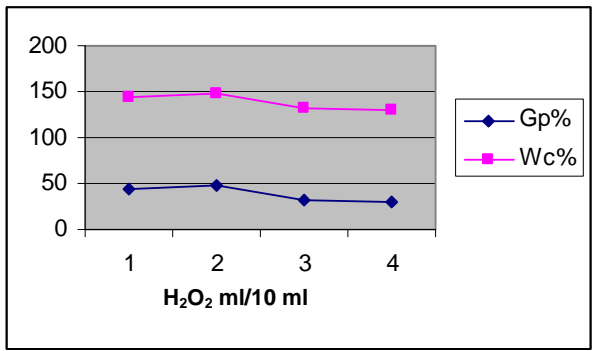

Figure 3. Effect of $\left[\mathrm{H}_{2} \mathrm{O}_{2}\right]$ on the grafting of AMPS onto WR (at 7 days; $90^{\circ} \mathrm{C}$; AMPS $1.5 \mathrm{~g} / 10 \mathrm{ml}$ ).

relatively high concentration of $\mathrm{H}_{2} \mathrm{O}_{2}$, causes a reduction of grafting, as result of increasing of backbone termination prior to AMPS addition. Similar observation is mentioned by others $[23,24]$.

\subsubsection{Influence of AMPS Concentrations}

The increase in monomer concentration would be expected to increase both the GP\% and the molecular weight of grafting copolymer. Accordingly the results in Figure 4, shows that, as the AMPS concentration increase, there is an increase in $\mathrm{GP} \%$ and $\mathrm{WC} \%$. However at the relativity high concentration of AMPS the grafting will be decreased. Those can be attributed to an increase in homopolymer formation with increase of AMPS content, so that homopolymer is in competition with graft copolymerization [25].

\subsection{Polymer Characterization}

\subsubsection{IR Spectroscopy}

IR spectra are used to prove the grafting. Figure 5 shows that the IR spectra of sulfonated AMPS in a comparison with WR-g-AMPS polymers. The grafted copolymers showed the bands at $1033 \mathrm{~cm}^{-1}$ for sulfonic group, and at $1648 \mathrm{~cm}^{-1}$ for carbonyl group. In addition the absorbed band at $2905 \mathrm{~cm}^{-1}$ was assigned to CONH group [26].

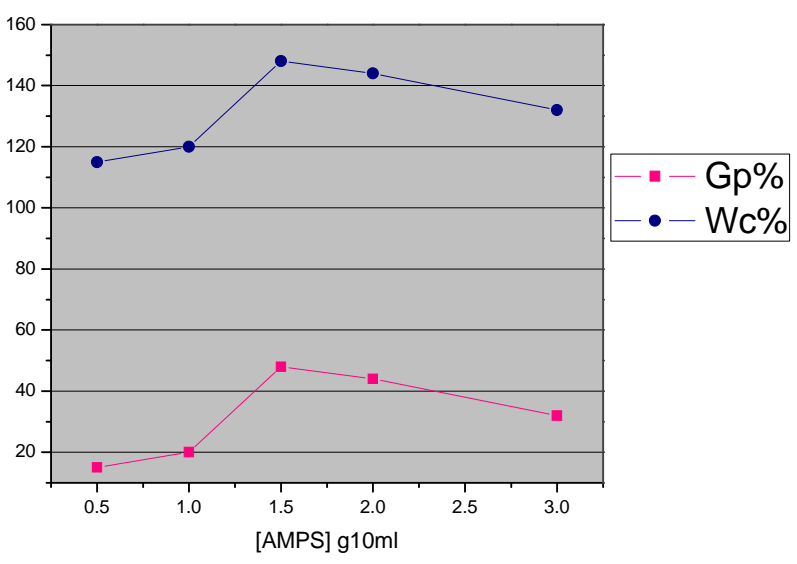

Figure 4. Effect of monomer concentration on the grafting of AMPS onto WR $\left(\mathrm{H}_{2} \mathrm{O}_{2} 3 \mathrm{ml} / 10 \mathrm{ml} ; 90^{\circ} \mathrm{C}\right.$; time 7 days).

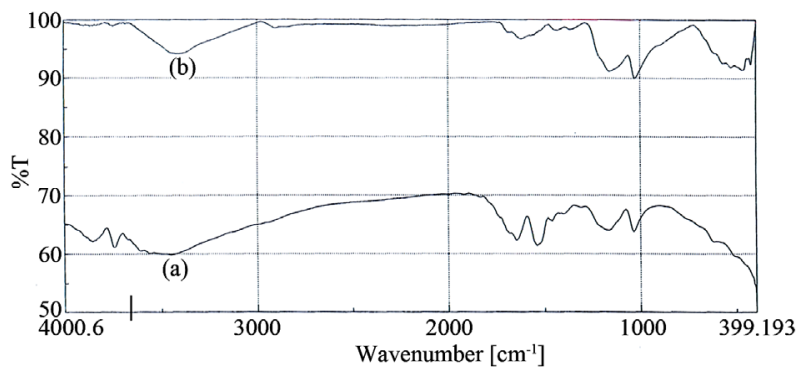

Figure 5. FT/IR spectra for WR-g-AMPS (a); and for sulfonated waste rubber (b).

These bonds indicate the penetration of AMPS within the waste rubber. Finally, the WR-g-AMPS was immersed in $\mathrm{NaOH}$ to get its sodium salt which is suitable for further applications. A suggested mechanism of the grafting reaction is represented in Figure 6.

\subsubsection{Thermal Characterization}

The DSC thermogram obtained for waste rubber is showed in Figure 7(a), it exhibits three exothermic peaks at 252,351 and $505^{\circ} \mathrm{C}$ and two endothermic peaks at 282 and $406^{\circ} \mathrm{C}$ respectively. Based on reaction transition temperature of exotherms and endotherms, the transition pyrolysis temperature ranges can be set at $206-282,283$ 406 and $407-500^{\circ} \mathrm{C}$. The first region are due to major product of pyrolysis are dipentene, the second are due to $\mathrm{C} 4$ hydrocarbons, and the third stage given high yields of $\mathrm{CH}_{4}, \mathrm{C} 2$ and $\mathrm{C} 3$ indicating the complete decomposition of rubber, according to data of Chen \& Quian [27], and by Miguel et al. [28].

On the other hand, the DSC curves for the grafted waste rubber Figure 7(b) exhibit one endothermic peak at about $105^{\circ} \mathrm{C}$ which are attributed to glass transition temperature $(\mathrm{Tg})$. Also there are two small peaks at high temperature about $380^{\circ} \mathrm{C}$ and $470^{\circ} \mathrm{C}$, which shows, the enhancement of the WR structure, by grafting of AMPS. These will be also indicated using SEM studies. 

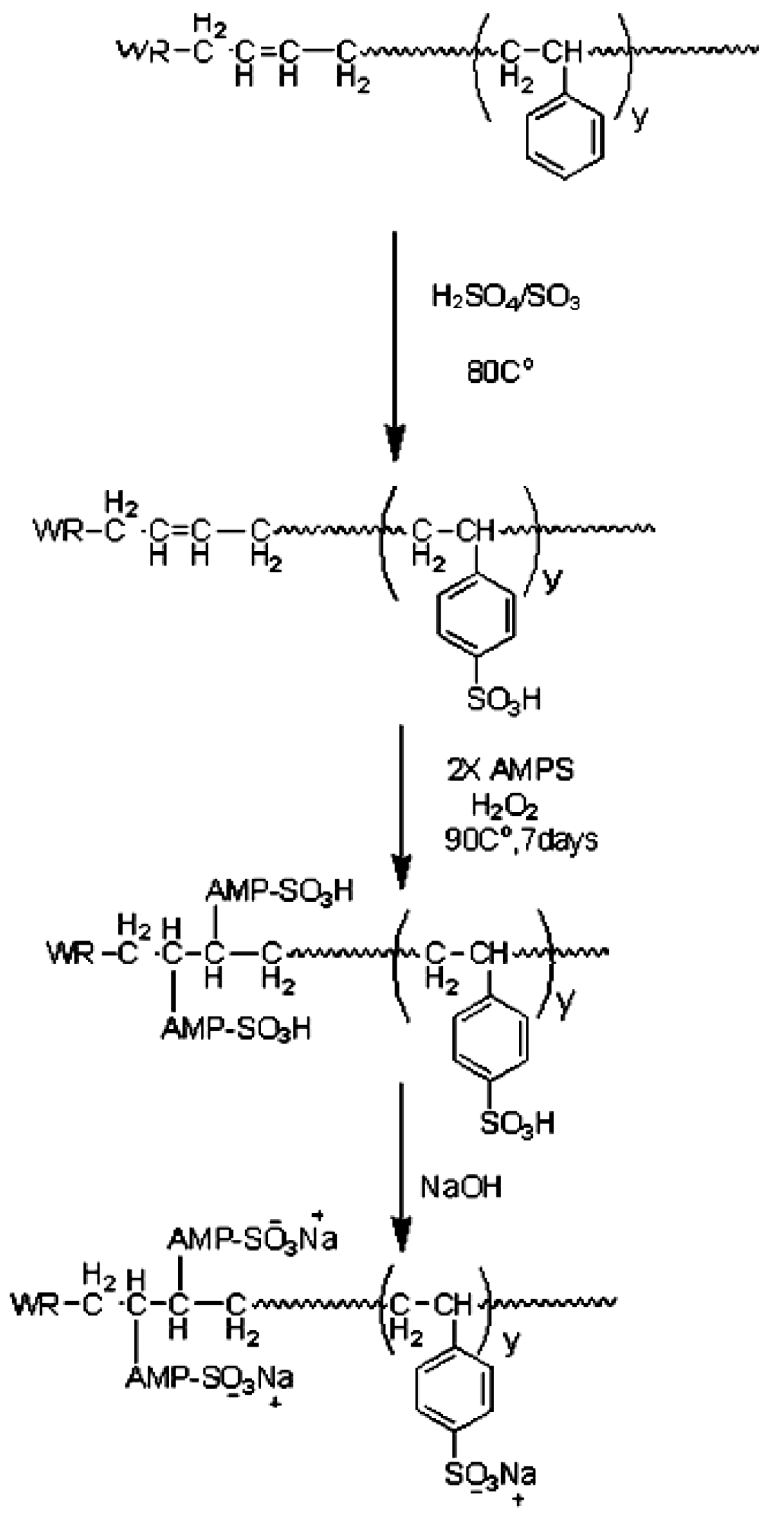

Figure 6. Suggested reaction mechanism for the grafting of AMPS onto scraped rubber.

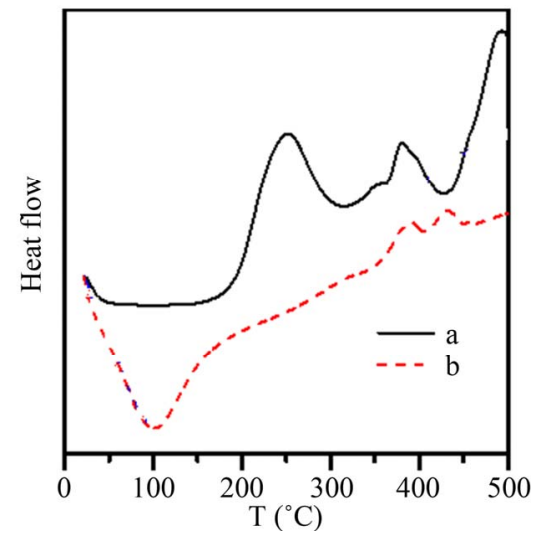

Figure 7. DSC curves for: (A) waste rubber; (B) WR-gAMPS.

\subsubsection{Morphology Studies}

The SEM micrograph of waste rubber shows inhomogeneous structure due to various industrial additives onto rubber Figure 8(a). However the SEM micrographs of sulfonated waste rubber Figure 8(b) show that the structure become relatively more homogeneous and the particle size decreased. On the other hand, the morphology of WR-g-AMPS, Figure 8(c) exhibits a relatively larger particle size and a higher crystallinity. Then from DSC and SEM measurements, the crystallinity of waste rubber is increased by the grafting with AMPS.

Futures of this work are progressed in our laboratory to remove different pollutants from industrial waste water, using such a treated waste rubber.

\section{Conclusion}

Recycling of scraped tires by grafting with AMPS is studied at various time, temperature, and concentrations of both initiator and monomers. The resulted materials are characterized using FTIR, DSC and SEM measurements. The grafted polymers were proved using FTIR analysis and the suggested reaction mechanisms are

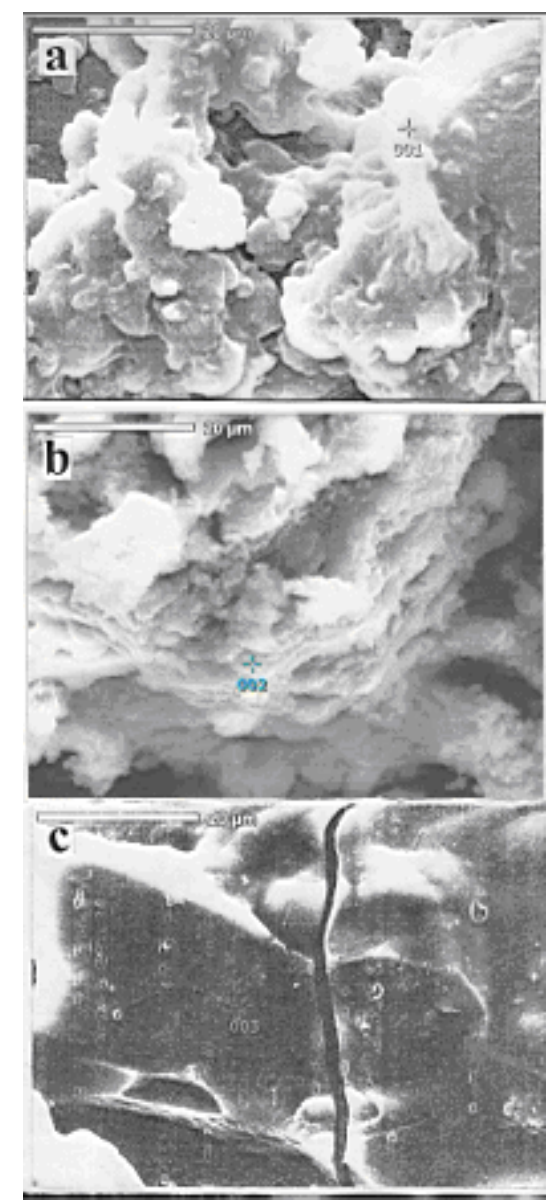

Figure 8. SEM micrograph for: (a) WR; (b) sulfonated waste rubber; (c) WR-g-AMPS. 
given. From DSC and SEM studies of WR-g-AMPS compared with PAMPS and WR, the result shows that the particle size and crystallinity were enhanced for the grafted polymers. The obtained grafted waste rubber materials are progressed in our laboratory as an ion exchanger for soil and water treatments.

\section{Acknowledgements}

The authors thankful to the kind support of King Abdulaziz City for Science and Technology (KACST), for the grant No. AP-25-18. The authors are also grateful for King Khalid University (KKU) for encouragements to do such research.

\section{REFERENCES}

[1] V. Makarov and V. F. DrozDovski, "Reprocessing of Tires and Rubber Wastes Recycling from the Rubber Products Industry," 1st Edition, Ellis Horwood, Chichester, 1991.

[2] G. Cheater and I. D. Loan, "Rubber and Plastic Research Association of Great Britain," Technical Review, Vol. 37, No. 13, 1966.

[3] M. R. Islam, H. Haniu and J. Fardoushi, "Pyrolysis Kinetics of Solid Tire Wastes Available in Bangladesh," Waste Management, Vol. 29, No. 2, 2009, pp. 668-677.

[4] J. Scheirs, "Polymer Recycling," Chap.12, Wiley, New York, 1998.

[5] G. M. Trofimora, D. D. Novikov, L. V. Kompaniets, T. T. Medintseva, Y. S. Yan and E. V. Prut, "Effect of the Method of Tire Grinding on the Rubber Crumb Structure," Journal of Polymer Science Part A, Vol. 442, No. 7, 2000, pp. 825-830.

[6] B. Adhikari and D. De Maiti, "Reclimation and Recycling of Waste Rubber," Progress in Polymer Science, Vol. 25, No. 7, 2000, pp. 909-948.

[7] F. Gavalieri, F. Cadella and F. Cataldo, "Mechanical Surface Activation of Ground Tire Rubber by Solid State Devulcanization and Grafting," Journal of Applied Polymer Science, Vol. 90, No. 6, 2003, pp. 1631-1638.

[8] F. Cataldo, O. Ursini and G. Angelini, "Surface Oxidation of Rubber Crumb with Ozone," Polymer Degradation and Stability, Vol. 95, No. 5, 2010, pp. 803-810. doi:10.1016/j.polymdegradstab.2010.02.003

[9] S. L. Zheng, Z. X. Zheng, K. Pal, Z. X. Xin, J. Suh and J. K. Kim, "Prediction of Mechanical Properties of Waste Polypropylene/Waste Ground Tire Powder Blends Using Artificial Neutral Networks," Material \& Design, Vol. 31 No. 8, 2010, pp. 3624-3629. doi:10.1016/j.matdes.2010.02.039

[10] C. T. Torrado, M. A. Franco, C. F. Gonzalez, M. A. Domingues and V. G. Serrano, "Development of Adsorbents from Used Tires Rubber, Their Uses in the Adsorption of Organic and Inorganic Solutes in Aqueous Solution," Fuel Processing Technology, Vol. 92, No. 2, 2011, pp. 206-212.

[11] S. Coiai, E. Passaglia and F. Ciardell, "Gradient Density
Grafted Polymers on Ground Tire Rubber Particles by Atom Transfer Radical Polymerization," Macromolecular Chemistry and Physics, Vol. 207, No. 4, 2005, pp. 2289 2298. doi:10.1002/macp.200600376

[12] N. Shahidi, F. Taeymour and H. Arastoopour, "Amphiphilic Particulate Phase Semi-Interepenetrating Polymer Networks Based on Recycled Rubber Matrix," Polymer, Vol. 45, No. 15, 2004, pp. 5183-5190.

[13] E. M. Adel-Bary, A. M. Dessouki., E. M. El-Neser and M. M. Hassan, "Radiation Induced Graft Copolymerization of Some Vinyl Monomers onto Waste Rubber Powder," Polymer-Plastics Technology and Engineering, Vol. 36, No. 2, 1997, pp. 241-256.

[14] A. Brydon, G. M. Burnett and G. G. Cameron, "FreeRadical Grafting of Monomers to Polydienes. II. Kinetics and Mechanism of Styrene Grafting to Polybutadiene," Jour- nal of Polymer Science, Vol. 12, No. 5, 1974, pp. 1011- 1021.

[15] Y. A. Aggour, A. S. Al-Shihri and M. R. Bazzt, "Recycling of Vulcanized Waste Rubber through Halogenations and Amination Chemical Reactions," WIT Transaction on Ecology \& Environment WIT Press, Vol. 120, No. 2, 2009, pp. 875-883.

[16] Y. A. Aggour, A. S. Al-Shihri and M. R. Bazzt, "Surface Modification of Waste Tire by Grafting with Styrene and Maleic Anhydride," Open Journal of Polymer Chemistry, Vol. 2, No. 2, 2012, pp. 70-76.

[17] J. Travaš-Sejdić and A. J Easteal, "Equilibrium Swelling of Poly(AAm-co-AMPS) Gels in Surfactant Solutions," Polymer, Vol. 41, No. 20, 2000, pp. 7451-7458.

[18] K. Ito and T. Shibano, "Process for the Preparation of Water Absorptive Composite Material," Mitsubishi Petrochemical Co. Ltd., Kokai, 1988.

[19] M. Matsukata, M. Hirata, J. P. Gong, Y. Osada, Y. Sakurai and T. Okano, "Two-Step Surfactant Binding of Solvated and Cross-linked Poly(N-propylacrylamide-co(2-acrylamido-2-methyl propane sulfonic acid)," Colloid and Polymer Science, Vol. 276, No. 12, 1998, pp. 11.

[20] Y. A. Aggour, "Reaction Kinetics of Graft Coolymerization and Thermochemical Studies of the Degradation of Some PVA Graf Copolymer," Polymer International, Vol. 50, No. 4, 2001, pp. 347-353.

[21] D. Hunkeler, "Macromolecules Mechanism and Kinetics of the Persulfate-Initiated Polymerization of Acrylamide," Macromolecules, Vol. 24, No. 9, 1991, pp. 2160-2171. doi: $10.1021 / \mathrm{ma} 00009 \mathrm{a} 004$

[22] C. Nakason, A. Kaesaman and P. Supasanthitikul, "The Grafting of Maleic Anhydride onto Natural Rubber," $P_{O}$ lymer Testing, Vol. 23, No. 1, 2004, pp. 35-41. doi:10.1016/S0142-9418(03)00059-X

[23] Y. A. Aggour, G. Bekhat and A. M. Atia, "Copolymerization and Thermal Investigation of AMPS with Acrylonitrile," Journal of Polymer Materials, Vol. 17, No. 3, 2000, p. 193.

[24] Y. A. Aggour, "Modification of Polystyrene Properties through N-vinylcarboxamido-2-methylpropanesulfonic Acid Monomer," Polymer International, Vol. 53, No. 12, 2004, pp. 1930-1935. doi:10.1002/pi.999

[25] J. T. Guthrie and P. D. Dune, "The Preparation, Charac- 
terization, and Application of Cellulose-MMA Graft Copolymers. I. The Aqueous-Based Preparation of Cellulose-MMA Graft Copolymers," Journal of Polymer Science Part A: Polymer Chemistry, Vol. 29, No. 9, 1991, pp. 1301-1312.

[26] L. J. Bellamy, "The Infrared Spectra of Complex Molecules," Wiley, New York, 1964.

[27] F. Chen and J. Quian, "Studies of the Thermal Degrada- tion of Waste Rubber," Waste Management, Vol. 23, No. 6, 2003, pp. 463-467.

[28] G. S. Miguel, J. Aguodo, D. P. Serrano and J. M. Escola, "Thermal and Catalytic Conversion of Used Tyre Rubber and Its Polymeric Constituents Using Py-GC/MS," Applied Catalysis B: Environmental, Vol. 64, No. 3-4, 2006, pp. 209-219. 